\title{
Pendampingan Penerapan Sistem Informasi pada Pos Kesehatan Paroki Keluarga Kudus Yogyakarta
}

\author{
Kristian Adi Nugraha ${ }^{\# 1}$, Danny Sebastian" ${ }^{\# 2}$, Maria Nila Anggia Rini\#”3 \\ 1adinugraha@ti.ukdw.ac.id \\ 22danny.sebastian@staff.ukdw.ac.id \\ 3nila@staff.ukdw.ac.id \\ \#1,2,3Informatika,Universitas Kristen Duta Wacana Yogyakarta
}

\begin{abstract}
Paroki Keluarga Kudus Yogyakarta want to implementing information technology system on its medical service activity because its administration process was not effective and efficient at all. But the problem is they didn't have any human resources that capable to implementing information technology system. So, they ask Fakultas Teknologi Informasi Universitas Kristen Duta Wacana to accompany them for implementing information technology on their medical service activity.
\end{abstract}

Keywords-gereja,sistem informasi, pelayanan kesehatan

\section{PENDAHULUAN}

Latar Belakang Masalah

Paroki Keluarga Kudus Banteng merupakan sebuah gereja yang diresmikan dan diberkati pada tanggal 1 Januari 1968 untuk dapat sudah dapat difungsikan untuk melayani sakramen [1]. Gereja ini terletak di Kecamatan Ngaglik, Kabupaten Sleman, Provinsi Daerah Istimewa Yogyakarta dengan 5000 orang yang tercatat sebagai anggota gereja di dalamnya [2]. Selain aktivitas pelayanan rutin seperti ibadah misa, Gereja Paroki Keluarga Kudus Banteng juga rutin mengadakan pelayanan tambahan, salah satunya adalah pelayanan pemeriksaan kesehatan. Kegiatan pelayanan kesehatan ini berlangsung setiap hari Minggu pukul tujuh pagi sampai dengan selesai. Kegiatan pelayanan ini bertempat di Panti Paroki Gereja Keluarga Kudus Banteng seperti yang terlihat padaGambar 1. Jenis pemeriksaan yang dilakukan meliputi pengecekan tensi dan kadar gula darah. Jumlah peserta dalam tiap kegiatan pelayanan kesehatan ini mencapai sekitar 50 orang yang didominasi oleh para lanjut usia.

Saat ini proses administrasi pelayanan kesehatan dilakukan secara tertulis, yaitu dengan mencatat di dalam buku dan biodata setiap peserta akan dicatat dalam sebuah media berbentuk kartu. Terdapat beberapa permasalahan yang diakibatkan dari penggunaan media konvensional tersebut, salah satunya adalah apabila terdapat perubahan informasi biodata seperti alamat, maka seluruh informasi yang ada harus disalin ke dalam media kartu yang baru, karena tulisan pada kartu lama tidak dapat dihapus. Permasalahan lain adalah semakin banyak jumlah pasien yang terdaftar dalam pos pelayanan kesehatan, maka petugas akan semakin kesulitan dalam mencari kartu anggota tersebut ketika hendak digunakan untuk keperluan administrasi. 


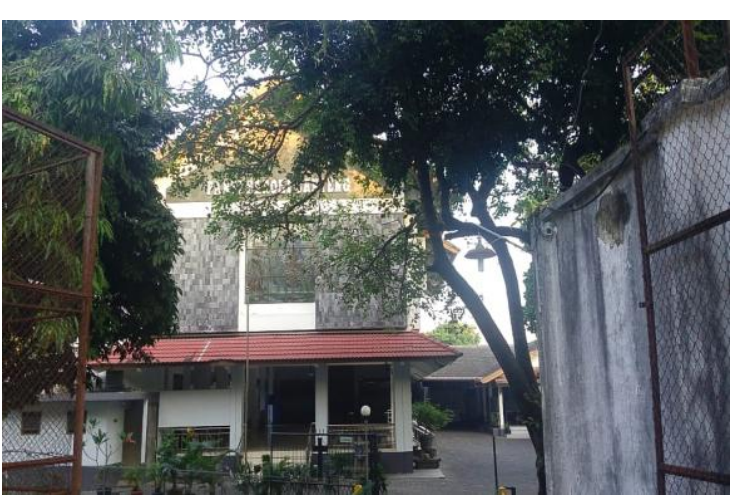

Gambar 1. Tempat Kegiatan Pelayanan Kesehatan

Melihat permasalahan tersebut, pihak panitia pelayanan pos kesehatan memiliki gagasan untuk menerapkan teknologi informasi dalam aktivitasnya, sehingga sebagian proses administrasi dapat dilakukan lebih efektif dan efisien. Beberapa keuntungan dengan adanya penerapan teknologi informasi adalah petugas pelayanan kesehatan dapat mengambil data anggota dengan cepat, karena cukup dengan mengetikkan sebagian informasi terkait dengan pasien seperti nama atau alamat [3]. Proses perubahan data juga dapat dilakukan dengan lebih mudah tanpa perlu menyalin seluruh data yang sudah ada sebelumnya seperti pada media kertas [4]. Keuntungan lain adalah implementasi teknologi informasi lebih menghemat tempat serta ramah lingkungan, karena seluruh informasi tidak berwujud fisik melainkan digital, tidak seperti pada media kertas yang membutuhkan tempat khusus untuk penyimpanan, terlebih jika jumlah informasi yang disimpan semakin banyak. Namun karena keterbatasan sumber daya manusia yang ada, maka pihak panitia pelayanan pos kesehatan meminta bantuan kepada Fakultas Teknologi Informasi Universitas Kristen Duta Wacana untuk melakukan pendampingan dalam implementasi teknologi informasi dalam aktivitas pelayanan kesehatan. Kegiatan pendampingan yang dilakukan meliputi pembangunan sistem informasi yang hendak diterapkan, hingga pelatihan kepada para calon pengguna sistem tersebut.

\section{Rumusan Masalah}

Permasalahan yang dihadapi oleh Gereja Paroki Keluarga Kudus adalah:

1. Admnisitrasi pelayanan kesehatan masih dilakukan secara konvensional, sehingga menyulitkan petugas saat proses pelayanan kesehatan berlangsung.

2. Pihak gereja ingin mengimplementasikan teknologi informasi di dalam pelayanan kesehatan, namun terkendala oleh kurangnya sumber daya manusia untuk proses implementasi.

Tujuan dan Manfaat

Tujuan dari diadakannya kegiatan pengabdian ini antara lain adalah:

1. Membangun sistem informasi pelayanan kesehatan untuk Paroki Keluarga Kudus untuk mempermudah proses administrasi.

2. Memberikan pelatihan kepada pihak gereja dalam menggunakan sistem informasi yang telah dibangun agar dapat mengoperasikannya dengan baik.

\section{METODE PENGABDIAN}

Proses pengabdian dilakukan dalam beberapa tahap. Tahap-tahap yang dilakukan dalam kegiatan pengabdian ini adalah sebagai berikut:

1. Diskusi Tatap Muka

Tahap ini bertujuan untuk menggali lebih dalam mengenaipermasalahan apa yang sebetulnya dijumpai oleh pihak panitia pelayanan pos kesehatan. Apabila permasalahan dapat diketahui secara rinci, maka akan semakin mudah untuk mendapatkan solusi yang paling tepat.

2. Studi Literatur

Tahap ini bertujuan untuk mencari solusi dari permasalahan yang telah didefinisikan sebelumnya. Penulis mencari referensi melalui literatur yang mengenai permasalahan serupa agar mendapatkan solusi yang paling optimal 
untuk diimplementasikan pada pelayanan pos kesehatan.

3. Pengembangan Sistem

Tahap ini diawali dengan membangun purwarupa [5] sistem informasi terlebih dahulu. Purwarupa ini dipresentasikan di hadapan calon pengguna, yaitu tim pelayanan pos kesehatan, guna memastikan apakah sistem yang dibangun telah sesuai dengan kebutuhan. Apabila purwarupa telah dianggap sesuai, maka tahap berikutnya adalah membangun sistem secara keseluruhan.

4. Pengujian

Pengujian dilakukan dengan 2 pendekatan, yaitu pendekatan black box testing dan pendekatan white box testing [6] [7]. Pada tahap ini, sistem akan diuji dan diperiksa apakah masih terdapat kesalahan sistem atau error dalam proses pengembangan sistem

5. Pelatihan

Pada tahap ini penulis melakukan pelatihan penggunaan sistem kepada para calon pengguna, yaitu tim pelayanan pos kesehatan. Pelatihan ini bertujuan agar para anggota tim dapat menggunakan sistem informasi tersebut dengan fasih. Selain itu, tahapan ini digunakan untuk memastikan tidak ada fitur yang belum diimplementasikan kepada sistem.

6. Pembuatan Dokumentasi dan Laporan

Pada tahap ini penulis mendokumentasikan seluruh kegiatan pengabdian masyarakat mulai dari pihak gereja mengajukan permohonan hingga seluruh aktivitas pengabdian dinyatakan selesai. Salah satu dokumentasi yang dihasilkan adalah deskripsi usecase, karena deskripsi usecase penting untuk menunjukkan proses sistem [8]. Pembuatan dokumentasi dan laporan ini juga merupakan bentuk pertanggungjawaban penulis kepada pihak gereja selaku pemohon serta pihak LPPM UKDW selaku pemberi dana.

\section{HASIL PELAKSANAAN}

Pengabdian diawali dengan adanya surat permohonan dari Romo Stephanus Fadjarianto, MSF selaku romo kepala di Paroki Keluarga Kudus Banteng pada tanggal 31 Januari 2019. Beliau mengajukan permohonan kepada Fakultas Teknologi Informasi Universitas Kristen Duta Wacana untuk memberikan bantuan berupa pendampingan dalam implementasi teknologi informasi di dalam salah satu kegiatan sosial pada paroki tersebut, yaitu pelayanan kesehatan.

Kendala utama yang dialami oleh paroki tersebut dalam menjalankan kegiatan pelayanan kesehatan adalah proses administrasi yang masih dilakukan secara konvensional pada media kertas dan buku, sehingga aktivitas pelayanan kesehatan menjadi kurang efektif dan efisien. Beberapa hambatan diantaranya adalah sulitnya mengubah data pasien karena harus menyalin ulang seluruh data yang lama ke media yang baru saat terjadi perubahan data. Selain itu proses pembuatan laporan bulanan harus dilakukan dengan cara merangkum data satu per satu, tidak dapat dilakukan secara otomatis. Dengan adanya penerapan teknologi informasi pada aktivitas pelayanan kesehatan, diharapkan segala proses administrasi dapat berjalan dengan lebih efektif dan efisien, sehingga menghemat waktu dan tenaga dari tim pos kesehatan.

Tahap pertama yang dilakukan oleh penulis adalah melakukan wawancaraawal pada tanggal 24 Februari 2019 untuk membahas apa yang dibutuhkan oleh petugas pelayanan kesehatan dan hal-hal yang terkait dengan jalannya proses pelayanan kesehatan. Proses wawancara ini dilakukan di Panti Paroki Gereja Keluarga Kudus Banteng, dengan narasumberadalah Ibu Lilik Saptowati selaku koordinator Pos Pelayanan Kesehatan dan tiga petugas administrasi, yaitu Ibu Sumini, Ibu Mariastuti, dan Ibu Sri Buntoro. Dalam pertemuan melakukan diskusi mengenai harapan yang diinginkan oleh petugas 
pelayanan kesehatan yang berkaitan dengan teknologi seperti yang terlihat pada Gambar 2 .

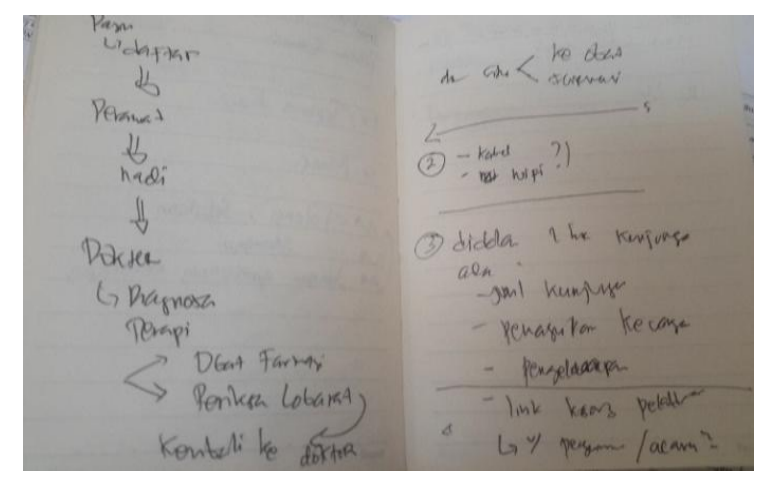

Gambar 2. Catatan Wawancara Awal

Setelah dilakukan wawancara awal, selanjutnya penulis melakukan wawancara lanjutan pada tanggal 3 Maret 2019 kepada tim pelayanan pos kesehatan. Wawancara dilakukan di rumah Ibu Sumini, salah satu dari tim pelayanan kesehatan. Proses wawancara terlihat pada Gambar 3.

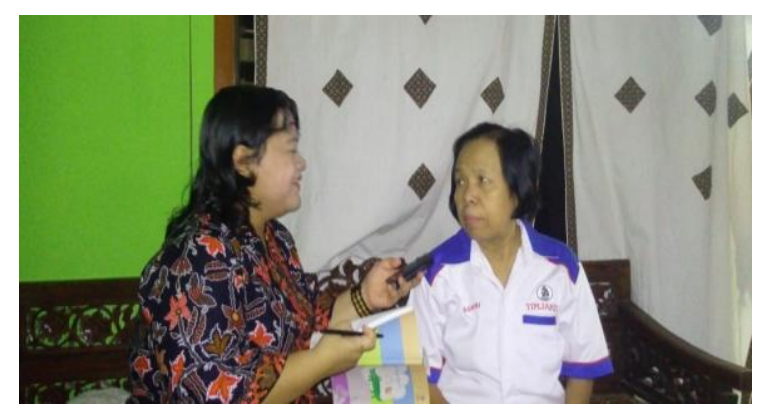

Gambar 3. Wawancara Lanjutan

Tahap ini dimaksudkan untuk menggali lebih dalam mengenai hal-hal apa saja yang dibutuhkan terkait dengan implementasi teknologi informasi di dalamnya. Beberapa pertanyaan yang diajukan oleh penulis meliputi:

1. Seperti apa proses administrasi yang berjalan saat ini?

2. Apa saja kendala yang dihadapi dalam proses administrasi?

3. Teknologi apa saja tersedia (komputer, internet, dan lain-lain)?

4. Seperti apa media yang digunakan tim untuk melakukan proses administrasi?
5. Apa keinginan tim pelayanan kesehatan untuk membantudalam melakukan pelayanan administrasi pendaftaran?

Berdasarkan diskusi dan observasi, didapatkan kendala utama yang dialami dalam menjalankan kegiatan pelayanan kesehatan yaitu proses administrasi yang masih dilakukan secara konvensional pada media kertas dan buku, sehingga aktivitas pelayanan kesehatan menjadi kurang efektif dan efisien. Pada Gambar 4 memperlihatkan proses administrasi yang masih manual. Salah satu contoh media yang digunakan tim pelayanan kesehatan adalah kartu biodata seperti yang ditunjukkan padaGambar 5 .

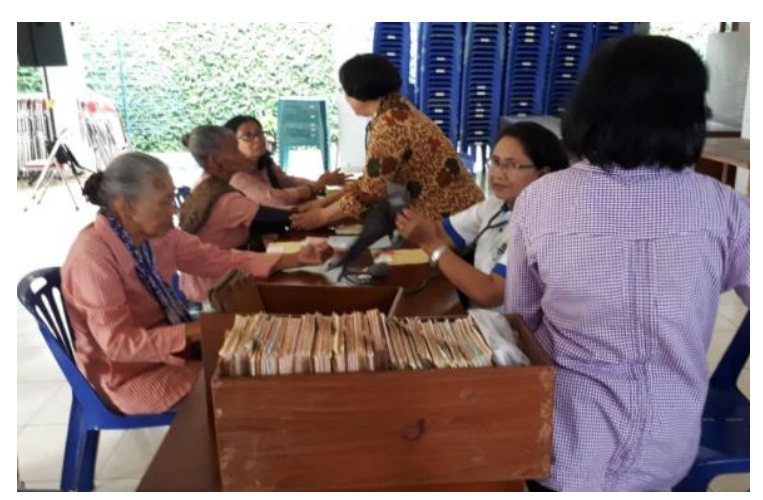

Gambar 4. Aktifitas Administrasi yang dilakukan manual

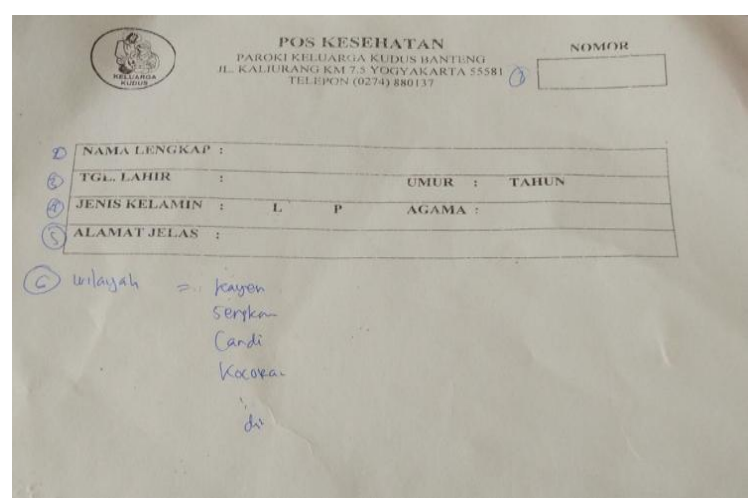

Gambar 5. Kartu biodata anggota pos kesehatan Gereja Paroki Keluarga Kudus

Penulis juga melakukan observasi secara langsung terhadap kegiatan pelayanan pos kesehatan di Paroki Keluarga Kudus seperti yang ditunjukkan 
padaGambar 6. Pelayanan kesehatan yang dilakukan di Paroki Keluarga Kudus meliputi dua jenis kegiatan, yaitu pemeriksaan tekanan darah dan pemeriksaan kadar gula darah. Kegiatan pelayanan kesehatan berlangsung setiap hari Minggu pada pukul tujuh pagi sampai dengan selesai dengan jumlah peserta mencapai kurang lebih 50 orang.

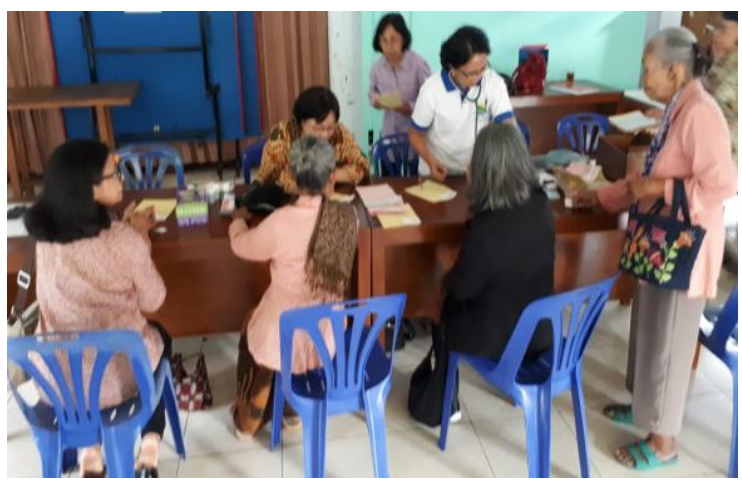

Gambar 6. Aktivitas pelayanan pos kesehatan Gereja Paroki Keluarga Kudus

Penulis mengumpulkan dan merangkum seluruh informasi yang berhasil diperoleh melalui tahap diskusi dan observasi. Langkah berikutnya, penulis melakukan analisa terhadap permasalahan yang dihadapi oleh tim pelayanan pos kesehatan secara rinci. Penulis juga melakukan studi literatur terkait dengan solusi yang dapat digunakan untuk menyelesaikan permasalahn tersebut. Dari hasil analisa yang telah dilakukan, terdapat dua hal yang menjadi catatan penulis:

1. Tidak adanya koneksi internet di area gereja. Hal ini menyebabkan sistem informasi yang dibangun tidak dapat berbasis online.

2. Laptop yang akan digunakan untuk implementasi sistem merupakan laptop keluaran lama, yaitu tahun 2007. Hal ini menyebabkan laptop tersebut tidak dapat menggunakan sistem operasi keluaran terbaru. Akibatnya versi teknologi yang digunakan adalah teknologi versi lama.
Berdasarkan kedua poin tersebut, penulis memutuskan untuk membangun sistem informasi berbasis desktop [9]dengan basis data terintegrasi yang ringan agar dapat berjalan pada laptop yang tersedia. Penulis memutuskan untuk membangun sistem informasi dengan menggunakan bahasa pemrograman Java versi 8 dan basis data SQLite [10].

Penulis melakukan pengembangan sistem secara bertahap. Pertama penulis melakukan pembuatan aplikasi kecil untuk memastikan aplikasi bisa berjalan dalam komputer petugas. Gambar 7 memperlihatkan bentuk purwarupa versi awal.

Selama bulan April 2019, penulis membangun purwarupa sistem informasi hingga dapat digunakan. Salah satu contoh tampilan antarmuka dari purwarupa sistem yang telah dibangun ditunjukkan pada Gambar 8 .

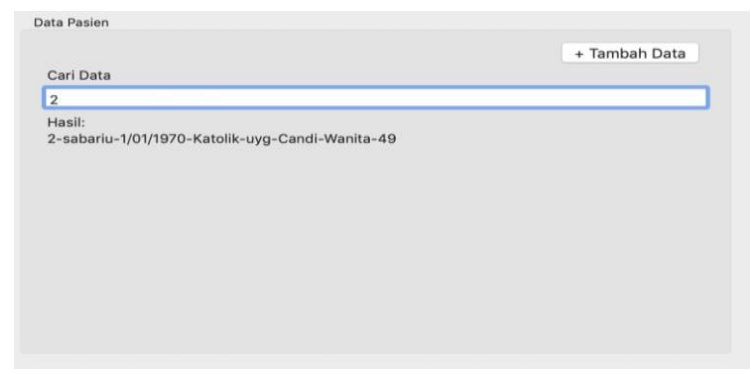

Gambar 7. Tampilan Antarmuka Pencarian data

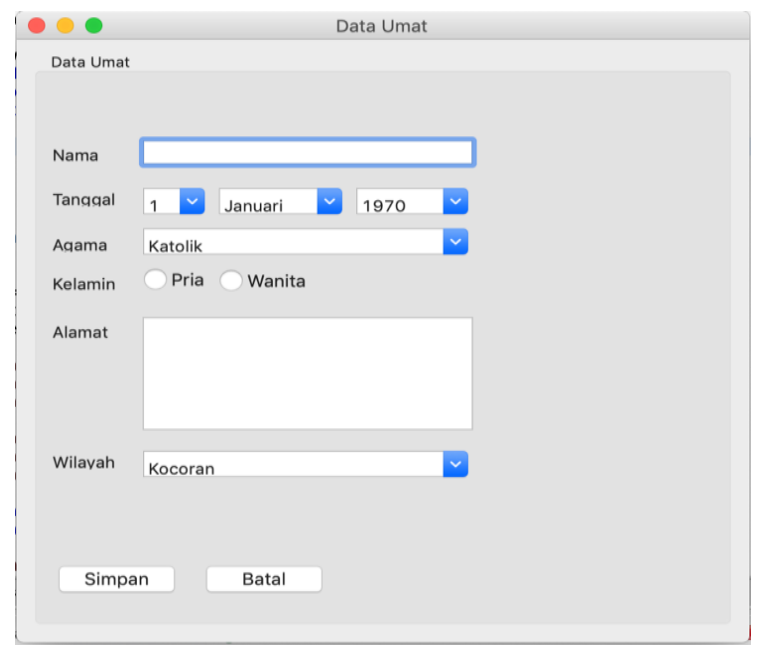

Gambar 8. Tampilan Antarmuka Tambah Data Umat 
Setelah dilakukan pembuatan purwarupa pertama, pada tanggal 7 April 2019, penulis melakukan presentasi sekaligus konfirmasi untuk aplikasi yang akan dibangun. Dari presentasi tersebut tim, mendapatkan beberapa masukan yaitu:

1. Untuk proses pencarian selain dengan nomor dan nama, namun juga dilakukan dengan pencarian dengan alamat. Kemudian tampilan data diperbaiki dengan memberikan tabel

2. Tulisan pada antarmuka terlalu kecil

3. Terdapat menu untuk menghasilkan laporan.

Penulis melakukan pembangunan system kembali dengan hasil presentasi pertama. Proses ini terus berlanjut selama bulan April, selain penulis melakukan pembangunan system selanjutnya sistem yang tersebut akan dipresentasikan kepada user. Proses ini dimaksudkan supaya sistem informasi tersebut benar-benar sesuai dengan kebutuhan tim administrasi pelayanan kesehatan Paroki Keluarga Kudus Banteng.Selain itu penulis ingin mencari tahu apakah masih terdapat kekurangan atau kebutuhan lain yang masih belum tercakup oleh sistem.

Setelah dilkukan pembangunan dan presentasi yang berkelanjutan, sistem yang telah selesai dibangun dipresentasikan kembali kepada pihak penulis pelayanan pos kesehatan pada tanggal 11 Mei 2019 seperti ditunjukkan padaGambar 9.Presentasi dilakukan di rumah Ibu Sumini. Pada tahap ini, penulis ingin memastikanapakah purwarupa dari sistem yang dibangun telah sesuai dengan harapan dan kebutuhan.

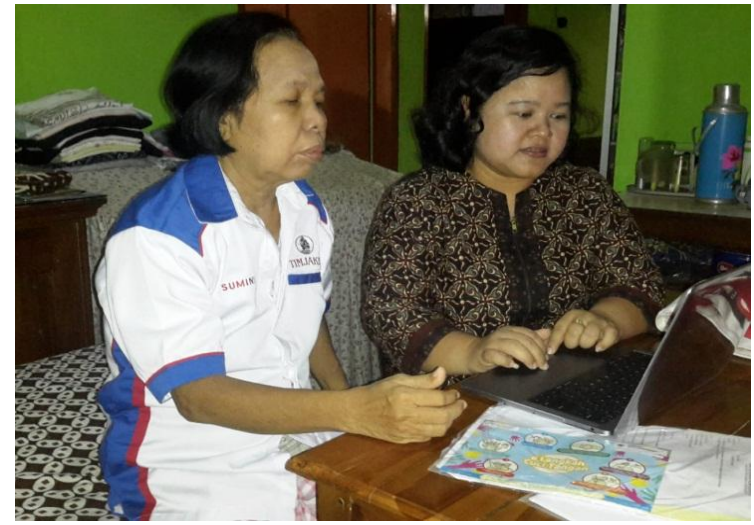

Gambar 9. Presentasi Purwarupa Sistem Informasi

Sampai dengan tahap ini, seluruh proses dapat terlaksana dengan baik.Tahap berikutnya yang harus dilakukan oleh penulis adalah melakukan pelatihan kepada para tim pelayanan pos kesehatan agar dapat menggunakan dengan fasih sistem informasi yang telah dibangun. Pelatihan dilakukan pada tanggal 19 Mei 2019 kepada tim pelayanan kesehatan. Pelatihan hanya dilakukan satu kali, karena sebelumnya aplikasi telah dilakukan presentasi setiap kali ada perbaikan sistem.

Kemudian tahap akhir adalah pembuatan dokumentasi. Penulis membuat dokumen dari sistem informasi yang dibangun hal ini dimaksudkan untuk mendokumentasi bagimana sistem informasi tersebut dibuat dan bagai mana cara penggunaannya. Sehingga jika nantinya ada perkembagan sistem akan dapat dilakukan dengan lebih mudah. Selain membuat dokumentasi sistem informasi, penulis juga melakukan pembuatan laporan kegiatan pengabdian masyarakat secara keseluruhan. Pembuatan dokumendokumen tersebut merupakan bentuk dari pertanggungjawaban penulis kepada pihak gereja Keluarga Kudus Banteng selaku pemohon serta pihak LPPM UKDW selaku pemberi dana. 


\section{KESIMPULAN}

Kesimpulan dari kegiatan pengabdian ini adalah sebagai berikut:

1. Kegiatan pengabdian masyarakat ini dapat terlaksana dengan lancar, sistem informasi yang dibutuhkan dapat dibangun dengan baik dan sesuai dengan kebutuhan.

2. Pihak petugas pelayanan kesehatan sangat kooperatif mulai dari tahap pengumpulan data hingga tahap pengembangan sistem informasi, sehingga segala proses pendampingan dapat berjalan dengan lancar.

Saran yang dapat penulis ungkapkan untuk kegiatan pendampingan penerapan teknologi informasi sejenis adalah masyarakat atau lembaga terkait hendaknya perlu mulai mempertimbangkan peremajaan peralatan-peralatan elektronik, khususnya peralatan digital seperti laptop dan komputer. Hal ini bertujuan agar penerapan teknologi informasi dapat menggunakan versi teknologi terbaru dan paling mutakhir.

\section{UCAPAN TERIMA KASIH}

Terima kasih kepada Lembaga Penelitian dan Pengabdian (LPPM) MasyarakatUniversitas Kristen Duta Wacana dan Paroki Keluarga Kudus Banteng Yogyakarta, terkhusus kepada Pos Pelayanan Kesehatan, yang telah mendukung kegiatan ini sehingga kegiatan pelatihan dapat dapat terlaksana dengan baik dan dapat menjadi bentuk pengabdian kepada masyarakat bagi dosen. Kegiatan pengabdian ini didanai oleh Lembaga Penelitian dan Pengabdian Universitas Kristen Duta Wacana, dengan nomor kontrak 032/D.02/LPPM/2019.

\section{DAFTAR PUSTAKA}

[1] Yacob, "Hole Family Church," 12 June 2011. [Online]. Available: http://yacobivan.blogspot.com/2011/06/holyfamily-church.html. [Accessed 4 January 2019].

[2] Y. D. Ratih, "PAROKI KELUARGA KUDUS BANTENG YOGYAKARTA: SEMANGAT KELUARGA MASA KINI," 28 June 2018. [Online]. Available: http://www.hidupkatolik.com/2018/06 /28/22738/paroki-keluarga-kudusbanteng-yogyakarta-semangatkeluarga-masa-kini/. [Accessed 4 January 2019].

[3] T. H. Davenport and J. E. Short, "The new industrial engineering: information technology and business process redesign," Center for

Information Systems Research, Sloan School of Management, Massachusetts Institute of Technology, 1990.

[4] D. Sebastian, K. A. Nugraha and N. Anggia, "Pendampingan Pembangunan Aplikasi Penilaian Guru SMA Kolese De Britto," in Prosiding Seminar Nasional Hasil Pengabdian kepada Masyarakat, Jakarta, 2018.

[5] H. A. Fatta, Analisis dan Perancangan Sistem Informasi untuk Keunggulan Bersaing Perusahaan dan Organisasi Modern, Yogyakarta: C.V Andi Offset, 2007, p. 185.

[6] S. Nidhra and J. Dondeti, "Black box and white box testing techniques-a literature review," International Journal of Embedded Systems and Applications (IJESA), vol. 2, no. 2, pp. 29-50, 2012. 
[7] M. E. Khan and F. Khan, "A comparative study of white box, black box and grey box testing techniques," Int. J. Adv. Comput. Sci. Appl, vol. 3, no. $6,2012$.

[8] D. Sebastian, "Rancang Bangun Website Klasifikasi Untuk Pencarian Produk Pasar Online Menggunakan Algoritma K-Nearest Neighbor," Jurnal Teknik Informatika dan Sistem Informasi, vol. 3, no. 3, 2017.
[9] PT. Solusi Aplikasi Interaktif, "PERBEDAAN APLIKASI DESKTOP DAN APLIKASI WEB," 21 Agustus 2018. [Online]. Available: http://developeraplikasi.com/perbedaa n-aplikasi-desktop-dan-aplikasi-web/. [Accessed 7 Juni 2019].

[10] Wahana Komputer, Tutorial 5 Hari Membangun GUI dengan JAVA Netbeans 6.5, T. A. Prabawati, Ed., Yogyakarta: C.V Andi Offset, 2010. 